\title{
Factors affecting internal standard selection for quantitative elemental bio-imaging of soft tissues by LA-ICP-MS $\dagger$
}

\author{
Christine Austin, ${ }^{a}$ Fred Fryer, ${ }^{b}$ Jessica Lear, ${ }^{a}$ David Bishop, ${ }^{a}$ Dominic Hare, ${ }^{a}$ Tristan Rawling, ${ }^{a}$ Les Kirkup, ${ }^{c}$ \\ Andrew McDonagh ${ }^{a}$ and Philip Doble $* a$
}

\author{
Received 23rd December 2010, Accepted 30th March 2011 \\ DOI: $10.1039 / \mathrm{c0ja00267d}$
}

\begin{abstract}
Element response variations under different laser ablation-inductively coupled plasma-mass spectrometry (LA-ICP-MS) operating conditions were investigated to identify important factors for selecting an internal standard (IS) for quantitative elemental bio-imaging. Analytes covering a range of atomic masses and first ionisation potentials (FIP) were selected to investigate the signal response variation with changes in laser spot diameter, mass bias and cell sampling position. In all cases, an IS improved experimental precision regardless of a close match in element mass or FIP but optimal analyte/IS combinations depended on the difference in masses of the analyte and IS. Particular attention was paid to ${ }^{13} \mathrm{C}$ as this isotope is typically used as an IS in elemental bio-imaging applications. Despite its non-ideal IS characteristics (often different mass and FIP to many analytes), possibility of abundance sensitivity effects and poor signal-to-background ratio, ${ }^{13} \mathrm{C}$ was a suitable IS candidate exhibiting a linear response with respect to the mass ablated, apparent independence from the high abundance of the adjacent ${ }^{14} \mathrm{~N}$ mass peak and effective analyte normalisation after background subtraction as long as the ${ }^{13} \mathrm{C}$ signal from the sample was at least $6 \%$ of the gross signal.
\end{abstract}

\section{Introduction}

A current challenge for elemental bio-imaging by laser ablationinductively coupled plasma-mass spectrometry (LA-ICP-MS) is the development of suitable calibration procedures to facilitate quantitative analyses. A common approach for quantitative elemental bio-imaging of soft tissues involves calibration using matrix-matched standards prepared from an appropriate matrix/ binder material (typically homogenised tissue) doped with the desired analytes. ${ }^{1-5}$ Calibration methods require the use of an internal standard (IS) to account for matrix effects as well as variations in mass ablated and transported, and instrumental drift. ${ }^{6,7}$ An effective IS should behave in a similar manner to the analyte during the ablation process and in the ICP, as well as be homogeneously distributed within the sample and standard matrices. ${ }^{6-8}$ For convenience, a minor isotope of a matrix element expected to be relatively uniformly distributed throughout the matrix is often selected as an IS. ${ }^{6}$

O'Connor et $a l .{ }^{9}$ recently proposed the online addition of water to the laser generated aerosol to improve the performance

${ }^{a}$ Department of Chemistry and Forensic Science, University of Technology Sydney, Sydney, NSW,2007, Australia.E-mail: Philip.Doble@uts.edu.au; Fax: +61 29514 1460; Tel: +61295141792

${ }^{b}$ Agilent Technologies Australia, North Ryde, NSW, Australia

${ }^{c}$ Department of Physics and Advanced Materials, University of Technology Sydney, Sydney, NSW, Australia

$\dagger$ Electronic supplementary information (ESI) available. See DOI $10.1039 / \mathrm{c} 0 \mathrm{ja} 00267 \mathrm{~d}$ of an IS (as the more robust plasma can buffer variations in sample load) and to aid in IS selection through investigations of matrix and fractionation effects when used with a matrixmatched CRM.

More conventional approaches in elemental bio-imaging applications for IS normalisation employ the ${ }^{13} \mathrm{C}$ signal. Increases in ${ }^{13} \mathrm{C}$ signal intensities are observed when soft tissue samples are ablated and this generally reflects the carbon concentration in the sample. However, $\mathrm{a}^{13} \mathrm{C}$ signal is observed in the background of the ICP-MS even when there is no ablation, arising from impurities in the argon gas, from the atmosphere, and from the walls of gas lines. ${ }^{10,11}$ Therefore the signal intensity of ${ }^{13} \mathrm{C}$ may vary independently from the analytes present in the sample due to a difference in the drift source. Additionally, ${ }^{13} \mathrm{C}$ has a significantly different atomic mass and/or first ionisation potential (FIP) $(11.26 \mathrm{eV})$ to many analytes (e.g., the first row transition metals have FIPs of $\sim 7 \mathrm{eV}$ ) and is non-uniformly distributed in some samples due to differences in tissue water content $^{12}$ and therefore this ion may not be an effective IS under some conditions.

We have previously reported a new approach to elemental bioimaging quantification using thin films, ${ }^{13}$ in which calibration standards were created by spiking thin polymer films with element standards. A soft tissue sample can be placed on top of a thin film containing an IS, and quantified using the calibration series. Tissue standards have also been used for a direct comparison of quantification within the two matrices. ${ }^{14}$ In this current work, we employ thin films and chicken breast standards 
to investigate the variation of analyte response over a number of changing LA-ICP-MS conditions. Analyte signal changes in response to tissue thickness and ablation volume, mass bias and cell sampling coordinates were measured. Additionally, abundance sensitivity effects on ${ }^{13} \mathrm{C}$ were investigated. These findings identify important factors affecting IS selection for quantitative elemental bio-imaging of soft tissues by LA-ICP-MS.

\section{Experimental}

\section{Thin film standards}

The preparation and characterization of thin films are described in detail elsewhere. ${ }^{13}$ Briefly, spin coating solutions were prepared from either poly(methylmethacrylate) (PMMA $M_{\mathrm{w}}$ 996000 , Aldrich, Germany) (10\%), $m$-xylene (+99\%, SigmaAldrich, Germany) (40\%) and chlorobenzene (99.8\%, SigmaAldrich, Germany) (50\%), and spiked with $1000 \mu \mathrm{g} \mathrm{mL}^{-1}$ metallo-organic standards (High Purity Standards, USA) or, poly (acrylic acid) (PAA $M_{\mathrm{w}} 450000$, Aldrich, Germany) (8\%) in Milli-Q water and spiked with $1000 \mu \mathrm{g} \mathrm{mL} \mathrm{m}^{-1}$ aqueous single element standards in 2\% (v/v) nitric acid (Choice Analytical, Australia). For the mass resolution experiments, poly(ethyleneimine) (PEI 50\% in $\mathrm{H}_{2} \mathrm{O}, M_{\mathrm{w}} 600000-1000$ 000, Fluka, Switzerland) films were prepared by spin coating single or multiple layers (5, 8 and 11 ) of a $20 \%$ polymer solution in Milli-Q water. A $200-400 \mu \mathrm{l}$ aliquot of the spin solution was micropipetted onto a cleaned quartz slide $(25 \times 25 \mathrm{~mm})$ placed on the vacuum chuck of a spin coater (model WS-400A-6NPP/LITE, Laurell Technologies Corporation, USA) and spun at $4000 \mathrm{rpm}$ for $40 \mathrm{~s}$ after allowing to sit for $10 \mathrm{~s}$. Solvents were removed by baking the films on a hot plate at 130 and $100 \pm 2{ }^{\circ} \mathrm{C}$ for 2 minutes for PMMA and PAA/PEI films, respectively. Films have a thickness variation of less than $2 \%$ and the majority of spiked elements give line scan RSDs of $\leq 5 \%$.

\section{Instrumental}

Analysis of film and tissue samples was performed via a quadrupole 7500cs ICP-MS (Agilent Technologies, Australia), coupled to a New Wave UP213 laser ablation unit (Kenelec Technologies, Australia). Most experiments employed the standard ablation chamber from New Wave (6 cm ID, $5 \mathrm{~cm}$ deep). A Large Format Cell $($ LFC) $(15.24 \times 15.24 \times 2.54 \mathrm{~cm})$ was also used in some experiments and is noted in the text. The LFC has a roving cup within the cell that moves with the laser to inhibit the spread of the aerosol. Standard operating parameters for the laser and ICP-MS are listed in the ESI (Table S1 $\dagger$ ). Deviations from standard parameters are noted in the text. Argon was used as the cell transport gas in all experiments. In all experiments a gas blank was collected prior to ablation of the sample for background correction.

\section{Tissue thickness and ablation volume effects}

Tissue sections prepared at different thicknesses were used to assess the linearity of the ${ }^{13} \mathrm{C} \mathrm{ICP-MS}$ signal response as a function of tissue thickness. Tissue samples were prepared by spiking a small portion of chicken breast with known amounts of single element aqueous standards and homogenising with an
OmniTech TH tissue homogeniser (Kelly Scientific, Australia). ${ }^{14}$ The homogenised tissue was pressed into a $15 \times 15 \times 5 \mathrm{~mm}$ mould and frozen in liquid nitrogen. The tissue was mounted in TissueTek O.C.T compound (ProSciTech, Australia) and cut using a Microm HM550 cryptome (Waldorf, Germany) fitted with C. L. Sturkey Diamond low profile microtome blades (ProSciTech, Australia) at 10-90 $\mu \mathrm{m}$. The tissue sections were dried before analysis. A stable signal was collected from each sample by ablating a line scan with enough laser power to completely ablate through the tissue $(30-45 \%$ or $0.05-2.0 \mathrm{~J} \mathrm{~cm}^{-1}$ ).

Linearity of the ${ }^{13} \mathrm{C}$ signal was also assessed against increasing laser spot diameter. Laser parameters were kept constant with spot diameter varied 15-100 $\mu \mathrm{m}$. A $30 \mu \mathrm{m}$ thick tissue standard was ablated.

\section{Abundance sensitivity}

The influence of abundance sensitivity (the overlap of an adjacent, more intense signal onto the measured signal) on ${ }^{13} \mathrm{C}$ signal intensity was investigated by measuring the signal from ${ }^{13} \mathrm{C}$ at different mass peak width settings with increasing amounts of nitrogen and carbon. The nitrogen concentration was increased by sampling increasing thicknesses of poly(ethyleneimine) (PEI) (molecular formula $\left.\left(\mathrm{C}_{2} \mathrm{H}_{5} \mathrm{~N}\right)_{n}\right)$ films and tissue standards. PEI films were prepared at $3,15,24$ and $33 \mu \mathrm{m}$ thickness by successive layers and tissue standards were sectioned at 10, 20, 30 and $40 \mu \mathrm{m}$. Since carbon and nitrogen were not constant in these experiments, the ratio of ${ }^{13} \mathrm{C}$ to ${ }^{14} \mathrm{~N}$ was measured.

The mass peak width was tuned by adjusting the AMU offset so that peak width at $10 \%$ of the peak height $(W-10 \%)$ of $12 \mathrm{~m} / z$ was $0.80,0.65$ or $0.40 \mathrm{amu}$ whilst ablating the NIST $612 \mathrm{CRM}$ glass standard. The AMU offset adjusts peak width for all masses uniformly. Data were acquired in spectrum mode (scanning at 20 points per mass). Signals $12-15 \mathrm{~m} / \mathrm{z}$ were monitored during ablation and peak heights, after background subtraction, were recorded. The pulse/analogue (P/A) factor for $m / z 13$ was optimised prior to analysis. The P/A factor is an Agilent 7500 ICP-MS instrument empirical correction to maintain linearity of the signal as the mode of acquisition automatically changes from pulsed to analogue. Analogue acquisition is required for signals above $1 \times 10^{6}$ counts per second. Abundance sensitivity was quantified by measuring the contribution of $9 \mathrm{~m} / \mathrm{z}$ on $8 \mathrm{~m} / \mathrm{z}$ from a $1 \mu \mathrm{g} \mathrm{g}^{-1}$ solution of $\mathrm{Be}$. As the mass of $\mathrm{Be}, \mathrm{C}$ and $\mathrm{N}$ is close, the abundance sensitivity of these masses was assumed to be similar. Be was used to quantify the abundance sensitivity due to the difficulty in measuring $14 \mathrm{~m} / \mathrm{z}$ in the absence of ${ }^{13} \mathrm{C}$.

\section{Signal intensity, element first ionisation potential and ablation volume}

The relationship between signal intensity, element first ionisation potential (FIP), and ablation volume (or sample load) was investigated by plotting various normalised signal intensities against ablation line width. In these experiments the laser fluence was kept constant as the spot size was modified by a rotating aperture wheel. A PAA film doped with $\mathrm{Fe}, \mathrm{Co}, \mathrm{Cu}, \mathrm{Zn}, \mathrm{Rb}, \mathrm{Y}$ and $\mathrm{Au}$ was analysed by ablating line scans at different laser spot diameters $(40-100 \mu \mathrm{m})$. The choice of elements represented low 
to high FIPs (4.2-9.2 eV). A plot of normalised signal intensity as a function of ablation area was constructed for each analyte/IS combination and the gradients calculated. All data were background subtracted before normalisation. The experiment was repeated for a tissue standard $(30 \mu \mathrm{m})$. Both a thin film standard and a tissue standard were analysed in duplicate in the standard cell and LFC.

\section{Mass bias}

The mass bias of the Agilent Technologies 7500cs ICP-MS may be altered by changing the voltage of the omega lens. Analyte behaviour in response to varied omega lens voltages was monitored. A PAA film doped with $\mathrm{Mg}, \mathrm{Cr}, \mathrm{Fe}, \mathrm{Co}, \mathrm{Cu}, \mathrm{Zn}, \mathrm{Rb}, \mathrm{Y}$ and $\mathrm{Au}\left(500 \mu \mathrm{g} \mathrm{g}^{-1}\right)$ was analysed at omega lens settings of 7.6, 8.4, 9.8 and 10.6 V. Background corrected analyte signals were plotted as a function of the changing conditions as both raw data and normalised data.

Additionally, line scans were ablated perpendicular to a previously ablated line (width $100 \mu \mathrm{m}$ ) so that a valley would appear in the scan when no material was ablated. The line scan was approximately $1 \mathrm{~mm}$ in length with an area of no film of about $100 \mu \mathrm{m}$ approximately in the centre of the line scan. The effectiveness of analyte/IS combinations was assessed by averaging the relative standard deviation (RSD) of three line scans acquired perpendicular to a previously scanned line. RSDs were calculated as the standard deviation divided by the mean signal response, converted to a percentage. Lower RSDs indicated a more effective IS as it was better able to correct non-uniformity in the line scan.

\section{Response variation and cell sampling coordinates}

The signal intensities of analytes at different sampling locations within the ablation chamber were compared. PMMA films, spiked with analytes, $\mathrm{Mg}, \mathrm{Fe}, \mathrm{Cu}$ and $\mathrm{Zn}\left(150 \mu \mathrm{g} \mathrm{g}^{-1}\right)$, and ISs, $\mathrm{Cr}, \mathrm{Y}$ (both $\left.25 \mu \mathrm{g} \mathrm{g}^{-1}\right)$ and $\mathrm{Ru}\left(5 \mathrm{mg} \mathrm{g}^{-1}\right)$, were analysed at nine separate locations, in random order, representing the extremities and centre of the sample cell. The sampling sequence was repeated twice in random order at six different gas flows at each of the nine locations. A Y-piece was connected before the torch so that the carrier gas flow rate could be varied $\left(0.6-1.2 \mathrm{~L} \mathrm{~min}^{-1}\right)$ whilst maintaining a constant gas flow to the plasma by addition of argon make-up gas.

To assess the effect of analyte/IS pair on accuracy, a calibration curve was constructed from sampling PMMA standards (50,100, 200 and $250 \mu \mathrm{g} \mathrm{g}^{-1}$ ) at the centre of the ablation chamber. This calibration curve was used to quantify the PMMA films sampled at the nine cell locations at one flow rate (1.2 $\mathrm{L} \mathrm{min}^{-1}$ carrier gas). Various ISs were employed at each of the nine locations and for the construction of calibration curves. Each analyte/IS combination was assessed against RSDs between locations and accuracy of quantification. All data were background subtracted before normalisation.

\section{Results and discussion}

Reported LA-ICP-MS analyses of tissues, ${ }^{\mathbf{1 5}}$ plastics, ${ }^{\mathbf{1 6}}$ botanical $^{17}$ and geological ${ }^{11}$ samples have utilised ${ }^{13} \mathrm{C}$ as an IS with mixed results. Normalisation to ${ }^{13} \mathrm{C}$ generally improved precision (compared to raw counts) for a variety of matrices ${ }^{18-22}$ although ${ }^{13} \mathrm{C}$ has been shown to be less sensitive to instrumental fluctuations than analytes. ${ }^{23}$ Transport and plasma effects may also vary between ${ }^{13} \mathrm{C}$ and analytes. A detailed investigation into the performance of ${ }^{13} \mathrm{C}$ as an IS was therefore undertaken and the results are discussed below. Elemental bio-imaging applications typically focus on elements of clinical importance (e.g., $\mathrm{Fe}, \mathrm{Cu}$ and $\mathrm{Zn}$ ) and therefore these elements were also investigated together with a number of other potential IS elements.

\section{Tissue thickness and ablation volume effects}

Tissue sections of homogenized chicken breast at different thicknesses were analyzed to assess the linearity of the ${ }^{13} \mathrm{C}$ signal as a function of tissue thickness. The ${ }^{13} \mathrm{C}$ signal intensity was linear $\left(R^{2}>0.97\right)$ over a tissue thickness range of $10-90 \mu \mathrm{m}$ using a laser power sufficient to ablate the entire tissue thickness. Linearity improved to $R^{2}>0.99$ after subtraction of the background ${ }^{13} \mathrm{C}$ signal. The ${ }^{13} \mathrm{C}$ signal is also linear $\left(R^{2}=0.9604\right)$ with increasing water content, a factor representative of cell density. ${ }^{12}$ These trends indicate that for situations where ${ }^{13} \mathrm{C}$ concentrations are proportional to the tissue density and thickness, ${ }^{13} \mathrm{C}$ is a suitable IS to compensate for variations in the ablated mass and in the mass transport efficiencies.

\section{Abundance sensitivity}

Abundance sensitivity describes the influence of an $\mathrm{m} / \mathrm{z}$ peak tail from an abundant isotope on another (usually adjacent) $\mathrm{m} / \mathrm{z}$ and is defined as the ratio of the two ion currents. ${ }^{24}$ In bio-imaging applications, there is potential for overlap of the ${ }^{14} \mathrm{~N}$ signal on the ${ }^{13} \mathrm{C}$ signal. This overlap could affect the performance of ${ }^{13} \mathrm{C}$ as an IS. This was investigated by measuring the peak heights of $12-15 \mathrm{~m} / \mathrm{z}$ at three mass peak widths at $10 \%$ peak height settings $(0.80,0.65$ and $0.40 \mathrm{amu})$ while ablating a series of nitrogencontaining films (PEI) and chicken breast tissue standards of increasing thickness.

The abundance sensitivity was quantified by measuring the contribution of $9 \mathrm{~m} / \mathrm{z}$ (Be 100\% natural isotope) on $8 \mathrm{~m} / \mathrm{z}$ (no elements with mass $m / z 8$ exist) with a $1 \mu \mathrm{g} \mathrm{g}^{-1}$ solution of Be.

Abundance sensitivity decreased (Table 1) when the mass peak width was reduced from 0.80 to 0.65 . Measurement at 0.40 mass peak width was similar to 0.65 indicating that the abundance sensitivity was eliminated at $1 \mu \mathrm{g} \mathrm{g}^{-1}$ Be. Similarly, any influence on the ${ }^{13} \mathrm{C}$ signal from the abundant ${ }^{14} \mathrm{~N}$ signal may be attributed to abundance sensitivity changes.

An increase in the ${ }^{14} \mathrm{~N}$ or ${ }^{15} \mathrm{~N}$ signal above the background was not observed for the PEI films or the tissue standards at any of the mass peak width settings. This was attributed to the very high blank signal at 14 and $15 \mathrm{~m} / \mathrm{z}$, which remained relatively constant despite increases in the $N$ content as the thickness of the standard films were increased. Therefore, the ${ }^{13} \mathrm{C}$ signal was not affected by

Table 1 Abundance sensitivity determined at different mass peak widths at $10 \%$ peak height values

\begin{tabular}{llll}
\hline Mass peak width $(W-10 \%)$ & 0.80 & 0.65 & 0.40 \\
Abundance sensitivity $^{a}$ & $4.68 \times 10^{6}$ & $13.3 \times 10^{6}$ & $14.5 \times 10^{6}$
\end{tabular}

${ }^{a}$ Measured as the ratio of $9 \mathrm{~m} / \mathrm{z}$ over $8 \mathrm{~m} / \mathrm{z}$ in a $1 \mu \mathrm{g} \mathrm{g}^{-1}$ solution of Be. 
changes in sample $\mathrm{N}$ content because of the overwhelmingly large background $\mathrm{N}$ signal. However, the ${ }^{13} \mathrm{C}$ signal may be affected by drift or fluctuations in the background ${ }^{14} \mathrm{~N}$ signal. The ${ }^{14} \mathrm{~N}$ signal fluctuated by up to $5 \%$ during analysis at a mass peak width setting. The ${ }^{13} \mathrm{C} /{ }^{14} \mathrm{~N}$ ratio increased with tissue thickness at all mass peak width settings with only a $15 \%$ difference between slopes (see ESI Fig. S2 $\dagger$ ).

The ${ }^{12} \mathrm{C}$ and ${ }^{13} \mathrm{C}$ signals both increased with tissue thickness at all mass peak width settings. The ${ }^{13} \mathrm{C} /{ }^{12} \mathrm{C}$ signal ratio should remain constant as the sample thickness increases. Variation in the ${ }^{13} \mathrm{C} /{ }^{12} \mathrm{C}$ signal ratio was generally low; RSDs were 6.6, 2.3, and $1.3 \%$ for $W-10 \% 0.80 \mathrm{amu}, 0.65 \mathrm{amu}$ and $0.40 \mathrm{amu}$, respectively. A decreasing trend in the ${ }^{13} \mathrm{C} /{ }^{12} \mathrm{C}$ ratio with increasing tissue thickness for $W-10 \% 0.8$ amu was observed. This may indicate an abundance sensitivity effect on the ${ }^{13} \mathrm{C}$ signal from the adjacent ${ }^{14} \mathrm{~N}$ signal (see $\mathrm{S} 2 \dagger$ ). ${ }^{12} \mathrm{C}$ may be used as an IS to avoid possible abundance sensitivity effects from ${ }^{14} \mathrm{~N}$, however the intense signal at $\mathrm{m} / \mathrm{z} 12$ may reduce the life of the detector.

\section{Signal intensity, element first ionisation potential and ablation volume}

A number of studies have investigated factors for predicting optimal analyte/IS pairs. Several reports have grouped elements together based on signal trends associated with ablation and/or ICP-MS conditions so that optimal analyte/IS pairs may be selected from within a group. ${ }^{\mathbf{8 , 2 5 , 2 6}}$ Some correlation between element properties within groups was reported. Several authors have noted the dominance of mass in selection criteria for a suitable analyte/IS pair, with FIP being of secondary importance. ${ }^{27-30}$ The effectiveness of an IS for a given analyte is dependent on the sample matrix and operating conditions used. ${ }^{30,31}$ Therefore, a study of element signal responses to varied LA-ICP-MS conditions is worthwhile to determine the factors that influence IS selection for elemental bio-imaging applications.

In the current work, the relationship between signal intensity, element first ionization potential (FIP) and ablation volume was investigated by measuring the signal intensity of a number of elements with a range of FIPs and mass at different ablation spot sizes. Experiments using thin film standards doped with a number of elements were performed to determine if the increase in sample load (from increasing spot diameter) changed the plasma and/or transport conditions and thus the amount of analyte ionised in the plasma. In these experiments, the film is completely ablated but the underlying quartz slide is not ablated. Importantly, the laser spot diameter is adjusted by selecting an appropriate aperture, and thus laser fluence remains constant throughout the set of experiments. We expect therefore that the nature of the ablation products (e.g., particle size distribution) remains reasonably invariant. The signal intensity of each element (for a particular ablation line width) was normalised to different ISs. All data were background corrected before normalisation.

Signal response to increasing ablation line width was different between the standard cell and large format cell (LFC) (see S3†). In the LFC, signal response was linear but in the standard cell signal response was only linear over $30-65 \mu \mathrm{m}$ and plateaued at
$80 \mu \mathrm{m}$ and beyond. Cell design was therefore responsible for the non-linear trends observed in the standard cell and not plasma loading from increasing mass ablated.

Irrespective of cell design and sample transport efficiency, an effective IS should compensate for sample transport efficiencies. Fig. 1 shows plots obtained from a thin film standard containing ${ }^{63} \mathrm{Cu}$ (FIP $7.73 \mathrm{eV}$ ) and ${ }^{66} \mathrm{Zn}$ (FIP $9.39 \mathrm{eV}$ ) normalised to ${ }^{13} \mathrm{C}$ (FIP $11.26 \mathrm{eV}$ ), ${ }^{59} \mathrm{Co}$ (FIP $\left.7.88 \mathrm{eV}\right),{ }^{85} \mathrm{Rb}$ (FIP $4.18 \mathrm{eV}$ ) and ${ }^{197} \mathrm{Au}$ (FIP $9.23 \mathrm{eV}$ ) in the standard ablation cell. All internal standards were effective for normalisation of the analytes regardless of a close match between FIP or mass (RSDs generally $<6 \%$ ). As expected, a close match in mass and FIP of the analyte/IS pair gave the greatest reduction in variation across the spot diameter range, though large differences in mass or FIP resulted in only a small deterioration in precision. Normalisation to ${ }^{13} \mathrm{C}$ yielded slightly higher RSDs for most elements.

A different trend was observed in the LFC (Fig. 1c and d). All IS elements showed effective normalisation at spot sizes greater than $65 \mu \mathrm{m}$. Below $65 \mu \mathrm{m}$, the ${ }^{13} \mathrm{C}$ IS was less effective compared to the other IS elements.

The experiment was repeated in the LFC with a tissue standard to provide greater signal intensity of the analytes below $65 \mu \mathrm{m}$ line widths. The thicker tissue section $(10 \mu \mathrm{m}$ tissue versus $1 \mu \mathrm{m}$ film standards) enabled the ${ }^{13} \mathrm{C}$ signal to increase substantially above the background when the tissue was ablated, as compared to thin film ablation. Under these conditions, ${ }^{13} \mathrm{C}$ was an effective IS across the whole spot diameter range (see $\mathrm{S} 4 \dagger$ ). These results indicate that for ${ }^{13} \mathrm{C}$ to be an effective IS, samples must generate a ${ }^{13} \mathrm{C}$ signal which accounts for at least $6 \%$ of the gross signal. The difference in the ${ }^{13} \mathrm{C}$ normalisation trend for thin film analysis in the standard cell compared to the LFC is because the thin film generates a ${ }^{13} \mathrm{C}$ signal greater than $6 \%$ of the gross signal at the $30 \mu \mathrm{m}$ spot diameter in the standard cell but does not produce sufficient signal $(<6 \%)$ in the LFC until the $65 \mu \mathrm{m}$ spot diameter. The difference in the ${ }^{13} \mathrm{C}$ signal-to-background ratio for the two cells may be explained by considering the difference in the amount of background ${ }^{13} \mathrm{C}$ present in the different instrument setups.

\section{Mass bias}

Experiments using thin films were performed with a laser spot size of $65 \mu \mathrm{m}$ (to provide a ${ }^{13} \mathrm{C}$ signal of sufficient intensity for effective normalisation) using omega lens settings of 7.6-10.6 V and the element signal trends were compared. The omega lens deflects the ion beam off axis approximately $5 \mathrm{~mm}$ into the quadrupole, which prevents photons and neutral species (which are not deflected) from entering the quadrupole. This leads to an improvement in the signal-to-noise ratio. The mass bias of the ICP-MS can be altered by changing the voltage of the omega lens. Generally, lower voltages increase the sensitivity to lighter elements and higher voltages to heavier elements. Elemental bioimaging experiments can run for more than $24 \mathrm{~h}$. It is possible that during the course of an imaging experiment, the mass bias may change due to the omega lens (or other lenses) becoming dirty. Non-ionised carbon atoms may recombine to form graphite on the relatively cold lenses, changing their optimum voltages. $^{32}$ 

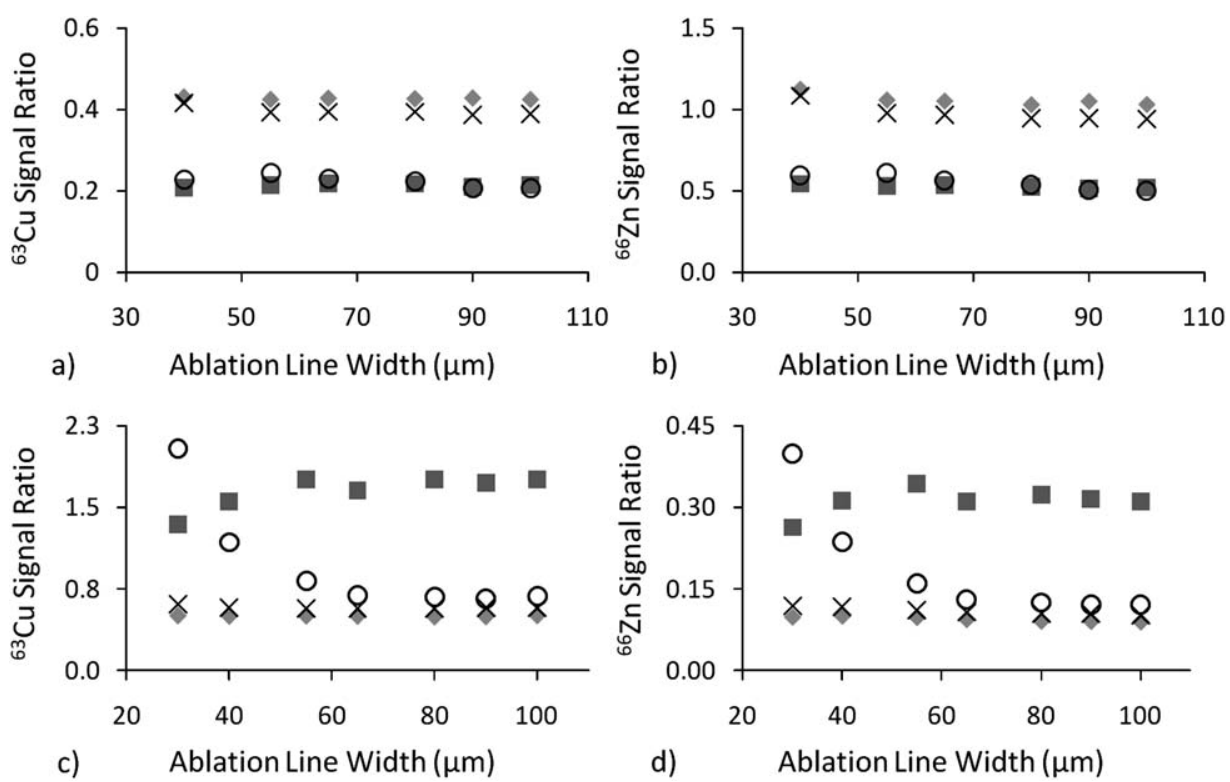

Fig. 1 Normalised ${ }^{63} \mathrm{Cu}$ and ${ }^{66} \mathrm{Zn}$ signal intensity ratios as a function of ablation line width using the standard ablation cell (a and b) and LFC (c and d). Analytes in the thin film were normalised to ${ }^{13} \mathrm{C}(\mathrm{O}),{ }^{59} \mathrm{Co}(\bullet),{ }^{85} \mathrm{Rb}(\times)$ and ${ }^{197} \mathrm{Au}(\boldsymbol{\square})$. In all graphs the ${ }^{63} \mathrm{Cu} /{ }^{13} \mathrm{C}$ and ${ }^{66} \mathrm{Zn} /{ }^{13} \mathrm{C}$ ratios are $\times 10^{-1}$.

During the course of a $15 \mathrm{~h}$ bio-imaging experiment, the NIST $612 \mathrm{CRM}$ was analysed every $3.5 \mathrm{~h}$ to observe any changes in mass bias. A number of light $\left({ }^{7} \mathrm{Li},{ }^{9} \mathrm{Be},{ }^{13} \mathrm{C},{ }^{24} \mathrm{Mg},{ }^{59} \mathrm{Co}\right.$, and $\left.{ }^{66} \mathrm{Zn}\right)$, mid-mass $\left({ }^{85} \mathrm{Rb},{ }^{89} \mathrm{Y},{ }^{115} \mathrm{In}\right.$, and $\left.{ }^{118} \mathrm{Sn}\right)$ and heavy elements $\left({ }^{208} \mathrm{~Pb}\right.$ and ${ }^{209} \mathrm{Bi}$ ) were monitored. Signal intensities varied between 21 and $61 \%$ during the experiment with the greatest variation observed for the light elements. When analytes were normalised to an IS close in mass, the variation in signal intensity was generally reduced to $<10 \%$ (see $\mathrm{S} 5 \dagger$ ). Normalisation to ${ }^{13} \mathrm{C}$ was not as effective as normalisation to another element close in mass at reducing the signal variation over time. This may be due to the different source of ${ }^{13} \mathrm{C}$ signal variation compared to the other elements. These data suggest that changes in the mass bias during the course of an elemental bio-imaging experiment may have significant effects on the chosen analyte/IS pair.

Elements of similar mass showed similar signal response trends over the omega lens voltage range but the magnitude of signal intensity increase/decrease varied considerably (Fig. 2a). As expected, element mass was the dominant factor for effective analyte/IS combinations determined from normalised signal intensities plotted against omega lens voltage (Fig. 2b-d). Midmass range elements were effectively normalised by ${ }^{52,53} \mathrm{Cr}$ or ${ }^{59} \mathrm{Co}$, whilst heavy elements were better normalised to a heavy element $\left({ }^{89} \mathrm{Y}\right)$. In contrast, normalisation of ${ }^{24} \mathrm{Mg}$ to mid-mass or heavy elements was more effective than to a light element such as ${ }^{13} \mathrm{C}$.

The normalised trends illustrate that certain analyte/IS combinations are more suitable at specific omega lens settings than others. For example, a small change in the mass bias under conditions where the omega lens is set to $9.8 \mathrm{~V}$ may produce a strong effect on the ${ }^{63} \mathrm{Cu} /{ }^{13} \mathrm{C}$ signal, whilst the ${ }^{63} \mathrm{Cu} /{ }^{59} \mathrm{Co}$ would remain relatively unchanged. The optimal analyte/IS pair at each omega lens setting was determined based on lowest \% RSD. Again, optimal analyte/IS combinations correlated with a close match in mass between analyte and IS (see S6†). Therefore, selection of analyte/IS pair should take into consideration the mass bias due to the omega lens setting.

\section{Mass abundance, FIP and ablation volume}

To ascertain whether the apparent abundance sensitivity effect observed for ${ }^{13} \mathrm{C}$ at mass resolution 0.8 would affect ${ }^{13} \mathrm{C}$ normalisation, the element FIP and ablation volume and mass bias experiments were repeated at the different mass resolutions and the results plotted in Fig. 3. There did not appear to be any significant difference in ${ }^{13} \mathrm{C}$ normalisation at the different resolution settings. Therefore, the overlap observed at a resolution of $W-10 \% 0.8$ amu did not reduce the performance of ${ }^{13} \mathrm{C}$ as an IS and therefore mass resolution may be optimised for specific applications without regard to the effect on ${ }^{13} \mathrm{C}$ as an IS.

\section{Response variation and cell sampling coordinates}

Poor sampling position reproducibility has been previously reported for the standard ablation cell when compared to open cell designs. ${ }^{33,34}$ Signal instability is usually a factor of distance from the gas inlet/outlet and uniformity of gas flow within the cell. ${ }^{35}$ Recently designed cells show superior sampling position stability and reproducibility by integrating open and closed cell designs. ${ }^{33,36}$

To assess analyte signal trends at various cell sampling coordinates, PMMA films were analysed at nine positions within the standard ablation chamber. Gas flow through the cell was also varied, with gas supply to the plasma kept constant by the addition of make-up gas via a Y-piece in front of the torch. For most elements, eight of the nine positions were uniform; for example $\mathrm{Zn}$ had an RSD of $4.2 \%$. Position 1, corresponding to the position nearest the cell gas inlet (see S7 $\uparrow$ ), showed higher signal intensities and increased the RSD for $\mathrm{Zn}$ to $29 \%$. This trend was seen for most elements but was more pronounced for ${ }^{66} \mathrm{Zn}$ and ${ }^{56,57} \mathrm{Fe}$. Additionally, ${ }^{89} \mathrm{Y}$ and ${ }^{101} \mathrm{Ru}$ showed a slight 


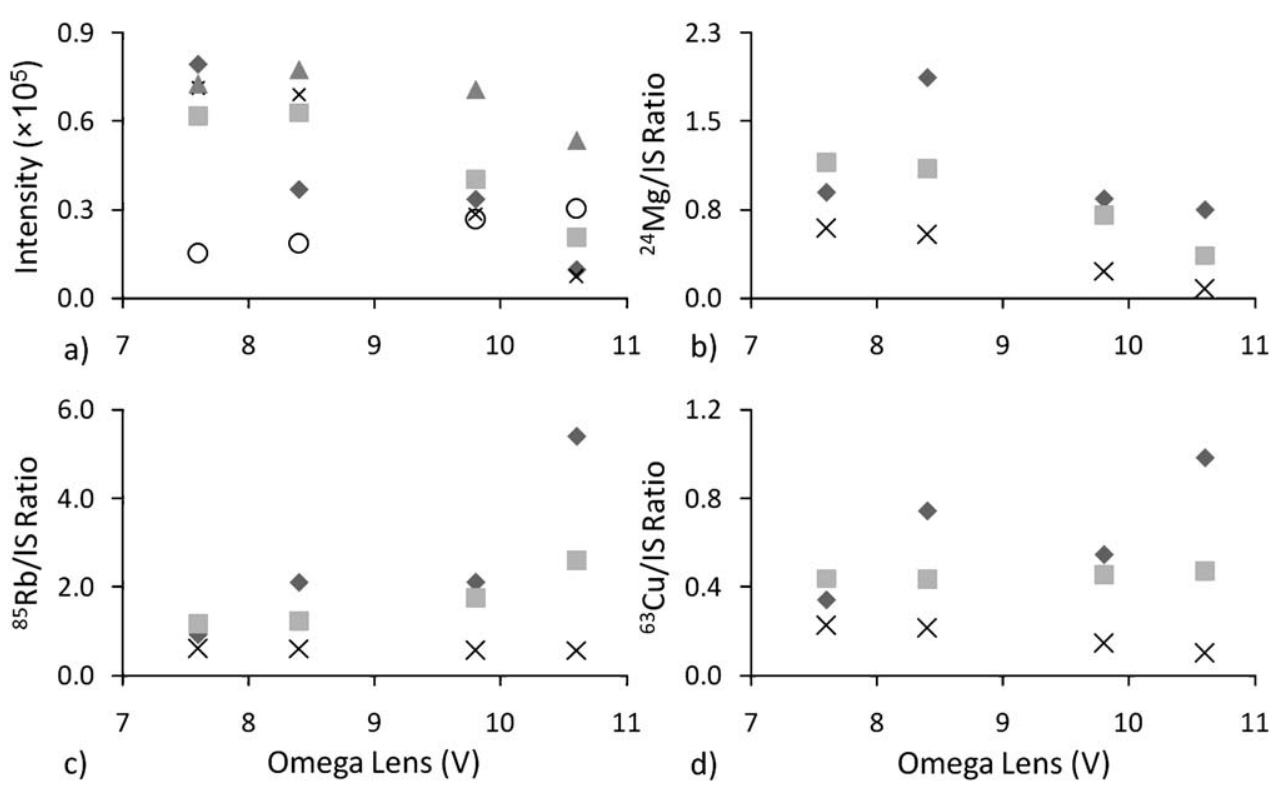

Fig. 2 Analyte response from thin film at different omega lens settings: (a) signal intensities of ${ }^{13} \mathrm{C}\left(\times 10^{-1}\right)(\bullet),{ }^{24} \mathrm{Mg}(\times),{ }^{59} \mathrm{Co}(\boldsymbol{\square}),{ }^{85} \mathrm{Rb}(\boldsymbol{\Delta})$ and ${ }^{197} \mathrm{Au}$ (O), (b) ${ }^{24} \mathrm{Mg}$ with normalisation, (c) ${ }^{85} \mathrm{Rb}$ normalisation and (d) ${ }^{63} \mathrm{Cu}$ with normalisation to ${ }^{13} \mathrm{C}(\times 10)(\bullet),{ }^{59} \mathrm{Co}(\mathbf{\square})$ and ${ }^{89} \mathrm{Y}(\times)$.
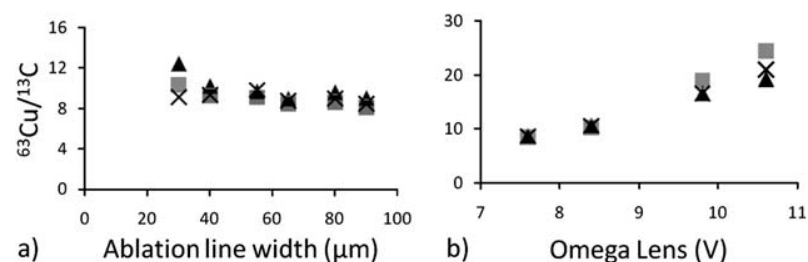

Fig. $3{ }^{63} \mathrm{Cu} /{ }^{13} \mathrm{C}$ response from signal intensity, element FIP and ablation volume (a), and mass bias experiments (b) at different mass resolutions. $0.8 \mathrm{amu}(\mathbf{\Delta}), 0.6 \mathrm{amu}(\boldsymbol{\square})$ and $0.4 \mathrm{amu}(\times)$.

decrease in signal intensity at position 1 . All elements investigated showed line scan RSDs of $<10 \%$.

There appeared to be little difference in analyte/IS pair signal stability across the sampling positions in the standard cell (see $\mathbf{S} 8 \dagger$ ). A larger difference in effectiveness of ISs was observed at position 1 for most elements. The most likely reason is the proximity of the Ar carrier gas inlet causing turbulence and unreliable mass transport.

IS efficacy was based on the degree of variation between positions after IS normalisation calculated as the RSD (Fig. 4). The lowest RSD for most analytes was with ${ }^{53} \mathrm{Cr}$ normalisation. The heavier elements, ${ }^{89} \mathrm{Y}$ and ${ }^{101} \mathrm{Ru}$, showed greatest stability when normalised to each other. This trend was repeated at all cell flow rates, though RSDs increased to over 50 and $70 \%$ for ${ }^{56,57} \mathrm{Fe}$ and ${ }^{66} \mathrm{Zn}$, respectively at carrier flow rates of $1.1-0.9 \mathrm{~L} \mathrm{~min}^{-1}$. The higher RSDs for ${ }^{56,57} \mathrm{Fe}$ and ${ }^{66} \mathrm{Zn}$ were due to a much larger signal increase at position 1 compared to all other analytes. Of note, normalisation with ${ }^{13} \mathrm{C}$ reduced RSDs for the mid-mass range of analytes compared to no normalisation.

The experiment was repeated in duplicate using the LFC. Analyte response variation across the LFC cell was less than 10\% RSD for most analytes without normalisation (see S9†). The large signal instability of ${ }^{56,57} \mathrm{Fe}$ and ${ }^{66} \mathrm{Zn}$ in the standard cell was not observed in the LFC. With normalisation, RSDs were reduced to $<4 \%$ (see $\mathrm{S} 9 \dagger$ ). The results show that the LFC, which incorporates open and closed cell designs, produces more stable and reproducible signal intensities throughout the cell for all analytes. The greater signal stability across different cell locations allows for a wider range of element candidates for IS. Additionally, the LFC has a faster washout time $(<5 \mathrm{~s})$ than the standard cell $(<15 \mathrm{~s})$ which could affect the imaging resolution of elemental bio-imaging applications.

To assess the significance of the signal variability in the standard cell on quantification, a set of PMMA calibration standards sampled in the centre of the standard cell (position 4) were used to quantify a PMMA film sampled at the nine different cell positions. The results showed that normalisation with ${ }^{52} \mathrm{Cr}$ generally gave the most accurate and precise quantification for the analytes (Table 2). ${ }^{13} \mathrm{C}$ and ${ }^{89} \mathrm{Y}$ gave the least accurate quantification. No single location was found to give more accurate quantification consistently, including position 4 at

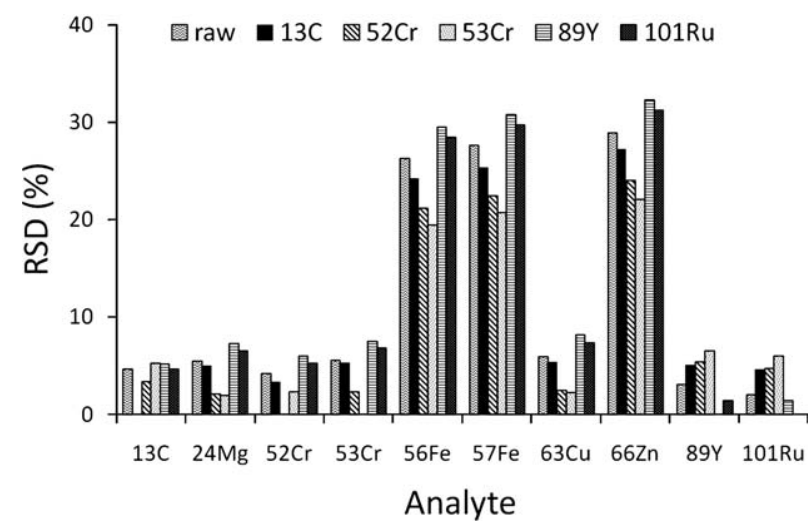

Fig. 4 Comparison of raw and IS normalised signal stability of analytes in standard ablation cell from ablation of a thin film. Analytes are normalised to ${ }^{13} \mathrm{C},{ }^{52} \mathrm{Cr},{ }^{53} \mathrm{Cr},{ }^{89} \mathrm{Y}$ and ${ }^{101} \mathrm{Ru}$ ISs. 
Table 2 Precision ( $\%$ RSD) and accuracy ( $\%$ difference between quantified and actual concentration) of quantification of analytes with different ISs

\begin{tabular}{|c|c|c|c|c|c|c|c|c|c|c|c|}
\hline \multicolumn{6}{|c|}{ Precision $(\%$ RSD) } & \multicolumn{6}{|c|}{ Accuracy ( $\%$ difference between quantified and actual concentration) } \\
\hline${ }^{13} \mathrm{C}$ & 2.28 & 2.35 & 3.22 & 2.03 & 3.84 & ${ }^{13} \mathrm{C}$ & -22.41 & -23.53 & -29.95 & -25.50 & -15.56 \\
\hline${ }^{52} \mathrm{Cr}$ & 0.84 & 3.27 & 3.96 & 0.98 & 3.18 & ${ }^{52} \mathrm{Cr}$ & 6.88 & 8.35 & -1.41 & -1.55 & 11.52 \\
\hline${ }^{53} \mathrm{Cr}$ & 2.12 & 4.00 & 5.17 & 2.28 & 4.07 & ${ }^{53} \mathrm{Cr}$ & 11.26 & 12.93 & 2.82 & 2.06 & 15.63 \\
\hline${ }^{89} \mathrm{Y}$ & 1.50 & 3.95 & 4.81 & 1.59 & 3.46 & ${ }^{89} \mathrm{Y}$ & 17.34 & 19.19 & 8.61 & 7.03 & 21.32 \\
\hline
\end{tabular}

which the standards were analysed. This highlights the need for an IS as the analyte response variation due to cell sampling positions appears to be non-reproducible.

\section{Summary}

The common practice of using ${ }^{13} \mathrm{C}$ as an IS is effective in compensating for the changing conditions likely to occur during an elemental bio-imaging experiment, despite having non-ideal IS characteristics such as different mass and FIP to most analytes. A linear response to both tissue thickness and ablation line width was observed for ${ }^{13} \mathrm{C}$. A slight abundance sensitivity effect on ${ }^{13} \mathrm{C}$ was observed at low mass resolution $(W-10 \% 0.80 \mathrm{amu})$ due to the high intensity of the adjacent ${ }^{14} \mathrm{~N}$ mass peak. However, this did not appear to affect the performance of ${ }^{13} \mathrm{C}$ as an IS. Therefore ${ }^{13} \mathrm{C}$ is an acceptable IS for elemental bio-imaging applications.

Various laser and ICP-MS parameters were varied to determine the response patterns of selected elements. Some general practical rules for selecting an effective IS for elemental bio-imaging applications arising from consideration of these experiments are:

1. Any IS is effective at compensating for changes in mass ablated, though ${ }^{13} \mathrm{C}$ is generally less effective than other IS elements.

2. For ${ }^{13} \mathrm{C}$ to be used as an effective IS, the sample must generate a ${ }^{13} \mathrm{C}$ signal at least $6 \%$ of the total gross signal.

3. A close match in mass and FIP between the analyte and IS results in the most effective IS, though a major difference in mass or FIP leads to a relatively small drop in IS effectiveness.

4. Mass bias may change over the course of an imaging experiment. To compensate for changes in mass bias, an IS close in mass to the analyte is recommended. Additionally, a close match in mass between IS and analyte generally improves precision at a given omega lens setting.

5. Analyte signal trends as a function of increasing sample load are dependent on cell design.

6. A close match in mass between analyte and IS produced the best compensation for signal instability across the cell sampling locations. Signal instability across cell sampling positions appears to be inconsistent and therefore use of an IS is particularly recommended for imaging experiments.

No single element was an ideal IS for all analytes. However, in agreement with a number of other publications, ${ }^{27,29,30}$ normalisation to any element, provided it has a uniform distribution, greatly improved precision. Although ${ }^{13} \mathrm{C}$ was an effective IS for elemental bio-imaging applications, development of a strategy to incorporate a more suitable IS (depending on the application) is encouraged.

\section{Conclusions}

We have investigated the factors that influence analyte signals in elemental bio-imaging applications. The results presented here offer useful insights into the factors that affect analyte response and the implications this may have on IS selection.

The signal trends of a selection of elements in response to changes in LA-ICP-MS operating conditions were investigated. Atomic mass tended to be the dominating factor in IS effectiveness when compensating for changes in mass ablated (ablation line width), mass bias or cell sampling position in a closed cell design. Signal stability across cell sampling locations was better in the LFC design. The LFC is therefore recommended for improved quantification over a wide spatial area. ${ }^{13} \mathrm{C}$ was a suitable IS candidate for LA-ICP-MS elemental bio-imaging applications as the response was linear with increasing mass ablated. ${ }^{13} \mathrm{C}$ IS performance was unaffected by abundance sensitivity effects.

\section{Notes and references}

1 J. Dobrowolska, M. Dehnhardt, A. Matusch, M. Zoriy, N. PalomeroGallagher, P. Koscielniak, K. Zilles and J. S. Becker, Talanta, 2008, 74, 717-723.

2 M. Zoriy, A. Matusch, T. Spruss and J. S. Becker, Int. J. Mass Spectrom., 2007, 260, 102-106.

3 J. S. Becker, M. V. Zoriy, M. Dehnhardt, C. Pickhardt and K. Zilles, J. Anal. At. Spectrom., 2005, 20,912-917.

4 J. S. Becker, M. V. Zoriy, C. Pickhardt, N. Palomero-Gallagher and K. Zilles, Anal. Chem., 2005, 77, 3208-3216.

5 J. S. Becker, A. Matusch, C. Depboylu, J. Dobrowolska and M. V. Zoriy, Anal. Chem., 2007, 79, 6074-6080.

6 S. F. Durrant, J. Anal. At. Spectrom., 1999, 14, 1385-1403.

7 D. Günther, S. E. Jackson and H. P. Longerich, Spectrochim. Acta, Part B, 1999, 54, 381-409.

8 H. P. Longerich, D. Günther and S. E. Jackson, Fresenius' J. Anal. Chem., 1996, 355, 538-542.

9 C. O'Connor, B. L. Sharp and P. Evans, J. Anal. At. Spectrom., 2006, 21, 556-565.

10 S. F. Durrant, Analyst, 1992, 117, 1585-1592.

11 S. Rege, S. Jackson, W. L. Griffin, R. M. Davies, N. J. Pearson and S. Y. O'Reilly, J. Anal. At. Spectrom., 2005, 20, 601-611.

12 M. V. Zoriy, M. Dehnhardt, A. Matusch and J. S. Becker, Spectrochim. Acta, Part B, 2008, 63B, 375-382.

13 C. Austin, D. Hare, T. Rawling, A. M. McDonagh and P. Doble, $J$. Anal. At. Spectrom., 2010, 25, 722-725, DOI: 10.1039/b911316a.

14 D. Hare, B. Reedy, R. Grimm, S. Wilkins, I. Volitakis, J. L. George, R. A. Cherny, A. I. Bush, D. I. Finkelstein and D. Doble, Metallomics, 2009, 1, 53-58.

15 M. C. Santos, M. Wagner, B. Wu, J. Scheider, J. Oehlmann, S. Cadore and J. S. Becker, Talanta, 2009, 80, 428-433. 
16 J. Marshall, J. Franks, I. Abell and C. Tye, J. Anal. At. Spectrom., 1991, 6, 145-150.

17 E. Hoffmann, C. Ludke, J. Skole, H. Stephanowitz, E. Ullrich and D. Colditz, Fresenius' J. Anal. Chem., 2000, 367, 579-585.

18 E. Hoffmann, C. Leudke, H. Scholze and H. Stephanowitz, Fresenius' J. Anal. Chem., 1994, 350, 253-259.

19 U. Narewski, G. Werner, H. Schulz and C. Vogt, Fresenius' J. Anal. Chem., 2000, 366, 167-170.

20 P.-H. Chi, F.-H. Ko, C.-T. Hsu, H.-L. Chen, C.-K. Yang, Y.-C. Sun and M.-H. Yang, J. Anal. At. Spectrom., 2002, 17, 358-365.

21 J. Feldmann, A. Kindness and P. Ek, J. Anal. At. Spectrom., 2002, 17, 813-818.

22 A. Kindness, C. N. Sekaran and J. Feldmann, Clin. Chem (Washington, DC, U. S. ), 2003, 49, 1916-1923.

23 B. Jackson, S. Harper, L. Smith and J. Flinn, Anal. Bioanal. Chem., 2006, 384, 951-957.

24 S. Richter, A. Alonso, W. De Bolle, R. Wellum and P. D. P. Taylor, Int. J. Mass Spectrom., 1999, 193, 9-14.

25 I. Rodushkin, M. D. Axelsson, D. Malinovsky and D. C. Baxter, $J$ Anal. At. Spectrom., 2002, 17, 1231-1239.
26 B. J. Fryer, S. E. Jackson and H. P. Longerich, Can. Min. J., 1995, 33, 303-312.

27 H. J. Finley-Jones, J. L. Molloy and J. A. Holcombe, J. Anal. At. Spectrom., 2008, 23, 1214-1222.

28 A. Tangen and W. Lund, Spectrochim. Acta, Part B, 1999, 54B, 18311838.

29 F. Vanhaecke, H. Vanhoe, R. Dams and C. Vandecasteele, Talanta, 1992, 39, 737-742.

30 J. J. Thompson and R. S. Houk, Appl. Spectrosc., 1987, 41, 801-806.

31 C. Sartoros and E. D. Salin, Spectrochim. Acta, Part B, 1999, 54, $1557-1571$.

32 M. A. Mesquita da Silva, V. L. Azzolin Frescura and A. J. Curtius, Spectrochim. Acta, Part B, 2000, 55B, 803-813.

33 J. Pisonero, D. Fliegel and D. Günther, J. Anal. At. Spectrom., 2006, 21, 922-931.

34 D. Bleiner and D. Günther, J. Anal. At. Spectrom., 2001, 16, 449-456.

35 C. C. Garcia, H. Lindner and K. Niemax, J. Anal. At. Spectrom., 2009, 24, 14-26.

36 Y. Liu, Z. Hu, H. Yuan, S. Hu and H. Cheng, J. Anal. At. Spectrom., 2007, 22, 582-585. 